Differences between staff groups in perception of risk assessment and risk management of inappropriate sexual behaviour in patients with traumatic brain injury

Marie Holland ${ }^{\mathrm{a}} \&$ Christine Norman ${ }^{\mathrm{a}}$

${ }^{a}$ Psychology division, School of Social Sciences, Nottingham Trent University, Nottingham, NG1 4FQ, United Kingdom

${ }^{1}$ corresponding author email christine.norman@ntu.ac.uk 


\section{Differences between staff groups in perception of risk assessment and risk management of inappropriate sexual behaviour in patients with traumatic brain injury}

This research explored staff perceptions of risk assessment and management of inappropriate sexual behaviour (ISB) displayed in patients following a Traumatic Brain Injury (TBI). The primary focus was to determine differences in perceptions between qualified $(\mathrm{N}=40)$ and direct care staff $(\mathrm{N}=47)$. Vignettes depicting ISB displayed by a male following a TBI were rated. The vignettes varied in behaviour (intimate versus non-contact) and age of the victim (child versus adult). Ratings for causal explanations (poor management, attention seeking, negative emotion and education), attributions (need for action and increase awareness) and emotions were analysed alongside risk assessment and management variables. Intimate contact ISB and ISB directed towards a child were perceived to be more serious and in need of intervention. Direct care staff perceived ISB to be due to sexual motivations, poor emotion control and to seek attention. They elicited greater negative emotions and based their judgements of risk on seriousness. On the other hand, qualified staff were more concerned about implementing interventions based on the risk of recurrence. Differences between staff groups could cause conflict regarding the assessment and management of ISB in TBI. Training to increase awareness of the behaviour could minimise differences and produce greater cohesion within clinical practice.

Keywords: traumatic brain injury; inappropriate sexual behaviour; risk assessment; risk management

\section{Introduction}

Determining the level of risk and appropriate management strategy are just some of the challenges staff members face when working with individuals with traumatic brain injuries (TBI) who display inappropriate sexual behaviour (ISB). This behaviour, along with other forms of challenging behaviour, can cause distress and discomfort for 
staff in inpatient settings (Johnson, Knight \& Alderman, 2006; Hayward, Robinson \& Knight, 2012).

Defining what constitutes ISB is not clear cut. From their research and due to a distinct lack of universality across existing literature Johnson et al (2006) devised a definition of ISB: "a verbal or physical act of an explicit, or perceived, sexual nature, which is unacceptable within the social context in which it is carried out" (p. 688). Within neurobehavioural institutions patient behaviour is closely monitored and recorded. Such task is often carried out by direct care staff - these staff also have the role of intervening using risk reduction strategies in unplanned situations.

The contextual aspect of the definition of ISB is pertinent to care settings in that if ISB was to occur outside of such institutional setting it could well be deemed a sexual offence, as depicted in the Sexual Offences Act 2003. This is not to say patients with TBI are exempt from a criminal conviction for displaying ISB (Simpson, Blaszczynski \& Hodgkinson, 1999) but within the context of a care setting behaviours tend to be managed rather than prosecuted. ISB is considered a sequela of brain injury. In comparison to physical and verbal aggression (Alderman, Knight \& Henman, 2002), ISB is a neglected area within the literature.

Perhaps because of the predominance of reported reductions in sex drive following TBI (Ponsford, 2003) prevalence of ISB following TBI is underestimated. In addition, the aforementioned uncertain definition of what comprises ISB, could also contribute to the lack of reporting (Johnson et al, 2006). Nevertheless, Simpson et al (1999) found that $6.5 \%$ of patients in rehabilitation services displayed ISB. More recent research reported an ISB prevalence rate of $8.9 \%$ over a 3 month period (Simpson, Sabaz, \& Daher, 2013). The most common type of ISB was inappropriate sexual talk 
(57.9\%), followed by touching (29.8\%) and exhibitionism/public masturbation (10.5\%). Other forms of challenging behaviour accompanied approximately $96 \%$ of the cases. It was also reported that those with more severe injuries were more likely to display ISB. Furthermore, Sabaz et al, (2014) found long duration post-traumatic amnesia was associated with ISB. Though previous research indicates a low prevalence, a staff survey highlighted $70 \%$ of rehabilitation staff reported sexual touching was common in their service (as cited in Bezeau, Bogod and Mateer, 2004). The presentation of ISB could therefore pose a complex challenge amongst rehabilitation professionals.

Risk assessment procedures are required to determine the likelihood and reduce the possibility of ISB occurring. Currently, standardised risk assessments are not validated within neurobehavioural environments (Alderman, Major \& Brooks, 2016). Observed behavioural data, for example using the St Andrews Sexual Behaviour Assessment (SASBA; Knight, Alderman, Johnson, Green, Birkett-Swan, \& Yorston, 2008), can assist these risk assessment procedures through determining patterns, antecedents and successful interventions. As it stands, many institutions devise their own risk assessment protocol which consists of an array of observed behavioural data, historical information and neuropsychological assessment data. Though there is a lack of consistency and standardisation across neurobehavioural services the information collected enables for a Structured Professional Judgement (SPJ) process (Weatherhead, Newby \& Skirrow, 2012).

Unlike actuarial risk assessments SPJ's allow for clinical judgement and a degree of professional discretion (Hart, 1998) which inevitably increases the level of subjectivity. Perceptions of risk and what is deemed to be the most appropriate means of intervention could be influenced by attributional responses of the clinician. Expert clinicians have been found to be influenced by attributional manipulations when 
assessing the level of dangerousness from case notes. They rated the client to be at increased risk when perceiving the behaviour to be internal to the client (Murray, Thomson, Cooke \& Charles, 2011). Results from this study, however, may be skewed due to the requirement that participants completed questionnaires for each behaviour scenario; responses to the previous scenario may somewhat influence the subsequent responses.

General public perceptions of sexuality regarding those with disabilities may well influence staff attributions, i.e, such individuals are asexual or sexually dangerous (Alexander \& Gomez, 2017). Due to the 'taboo' nature of disability and sexuality, few studies have explored causal attributions of staff in relation to patient ISB. When investigating ISB within a mild intellectual disability (ID) male population the behaviour was attributed as internal to the patient and uncontrollable by the staff, which was thus perceived to be more serious (MacKinlay \& Langdon, 2009). Staff in differing roles attribute internality differently (Smith \& Willner, 2004); the "more experienced" care managers rated ISB as less internal to the patient than did, "lesser experienced" direct care staff. Though qualified professionals determine the level of risk and the management strategies to reduce the likelihood of the behaviour occurring it is the direct care staff who regularly facilitate these interventions (Smith \& Willner, 2004). This study neglected the exploration of the staff member's role within the situation. Figures from a survey report $60 \%$ of rehabilitation staff did not feel adequately trained in dealing with ISB following TBI (as cited in Bezeau et al, 2004) and as staff interactions may impact on the cause and maintenance of maladaptive behaviour (Lambrechts, Kuppens, \& Maes, 2009),such attributional dimensions have been included in the present study. 
Much of the existing literature investigating staff factors which influence the response to 'challenging behaviour' is within ID or dementia environments. Staff causal attributions have been associated with emotional responses to the displayed behaviour. Negative emotions, such as anger, relate to the perceived internality of behaviour (Dagnan \& Cairns, 2005; Hayward, Robertson \& Knight, 2012). This emotional response can impact on the willingness of staff to engage in appropriate interventions (Tynan \& Allen, 2002). Though similar findings are presented for differing patient groups it is naïve to assume they are homogeneous. Research is needed to explore staff attributions to behaviour displayed by patients where the perceived causation is due to acquired deficits rather than developmental or progressive impairments.

In addition to attributions, perceptions of causal explanations can impact the responses and management of challenging behaviour (Pulsford, Duxbury \& Hadi, 2011). Few studies have explored this in relation to traumatic brain injury. The current literature draws on the idea that if visible disability markers are not present (which is often the case for TBI), individuals are likely to misattribute causal explanations. These explanations are more likely to fit with the observer's personal judgements, and not acknowledge brain injury as a casual factor (McClure, 2011). It is important to understand these possible explanations further as they may affect the level of care and support provided by staff to the patient. From adapting the Challenging Behaviour Attribution Scale (Hastings, 1997) Smith and Willner (2004) devised a list of explanations applicable to ISB (such as attempting to gain attention or lack of appropriate skills). Acknowledging that neurological impairments result in impulsivity and disinhibition (Lawrie \& Jillings, 2004) was also factored into the present questionnaire. 
Risk assessment and risk management concerns the prevention of adverse behaviour occurring (Hart, 1998). Within this the perception of seriousness could determine the management strategies implemented. Literature has shown responses to vignettes differ depending on topography and victim age. Intimate contact or noncontact ISB directed towards a child indicates a higher perceived need for intervention in comparison to ISB directed towards an adult (Smith \& Willner, 2004). Though vignettes have been scrutinised due to limited ecological validity (MacKinlay \& Langdon, 2009), for experimental consistency and control this methodology is replicated in the present study. It was important to include the variant of 'child' within the vignettes due to the occurrence of family visits within the grounds of many neurorehabilitation services.

Given the lack of research investigating the risk assessment and management of ISB in TBI, the use of a methodology similar to that conducted by Smith and Willner (2004) provides a good foundation to explore this matter. The current study compared the differing roles of qualified and direct care staff. Using vignettes, it aimed to establish the influence of psychological factors: (1) causal explanations, (2) attributions, and (3) emotional responses, on the perception of seriousness, risk of recurrence and management of ISB in TBI across two staff groups (direct care staff and qualified staff). Direct care staff are those who provide consistent day-to-day, somewhat hands-on, support for the patients, whereas, qualified staff are those in a more supervisory position and spend less contact time with the patients. Taking into consideration the nature of these different roles and acknowledging the many dependent variables the main hypothesis to be tested was: direct staff would elicit more negative emotions towards ISB than qualified staff and would also rate the need for greater management strategies and intervention. 


\section{Method}

\section{Participants}

Forty qualified staff participated in the research (mean age of 41.6 years with a mean of 7.8 years of experience, $72.5 \%$ were female). This group consisted of 22 qualified nurses and 18 Health and Care Professions Council (HCPC) registered professionals (including Physiotherapists, Dieticians, Occupational Therapists, Speech and Language Therapists and Psychologists). Forty-seven direct care staff also took part (mean age of 37.3 years with a mean of 5.6 years of experience, $72.3 \%$ were female).The participants were required to have 1 year minimum experience. As per UK prerequisite direct care staff required a good standard of literacy and numeracy, having obtained or working towards a vocational qualification in healthcare (Healthcare assistant, n.d.). During induction procedures all staff members were required to attend Brain Injury Awareness training. All participants worked in a neurobehavioural setting specialising in Traumatic Brain Injury where inappropriate sexual behaviour was a salient theme. Such environment consisted of 5 nursed wards and 5 staffed community houses where staff worked across both settings.

\section{Vignettes}

Similar to the design by Smith and Willner (2004) four vignettes with differing behaviour scenarios and victim ages were created. The behaviour consisted of noncontact (NC; shouting words of a sexual nature at a victim) and intimate-contact (IC; touching the victim's genitals). Such behaviour was directed towards either an adult patient from another service or a child. To ensure consistency, background information which depicted a 32 year old male with a traumatic brain injury, who engaged in this behaviour whilst residing in a staff-supported house in the community, was held constant across all conditions. 


\section{Questionnaire}

Demographic information (age, gender, ethnicity and years of experience with ISB and TBI) was collected at the beginning of the questionnaire. Following from the presentation of the vignette participants were required to answer questions about the outlined scenario in relation to their causal explanation, attributions, emotional responses and perceptions of risk assessment and management.

Participants were required to rate the likelihood of the ISB from a choice of 15 causal explanations. A 5-point Likert-scale was used with '0' representing 'very unlikely' and '4' representing 'very likely'. The majority of these listed explanations were validated by Smith and Willner (2004) and were deemed to be applicable to ISB (examples listed in Table 1). In acknowledgement that following a TBI individuals may present as impulsive (Lawrie \& Jillings, 2004) when engaging in such behaviour this factor was added to the original 14 explanations proposed in the previous research.

Causal attributions associated with the ISB were obtained from using 7 dimensions from a modified Attributional Style Questionnaire (Cottle, 1995; Peterson et al, 1982). Participants were asked to choose one of the 15 causal explanations which they felt most likely caused the depicted ISB. From that they were required to rate their responses of the specified cause on a 7-point Likert-scale for each of the 7 attributional dimensions. The dimensions include (1) locus (internal-external), (2) controllableuncontrollable, (3) global-specific, (4) personal-universal, (5) stable-unstable in relation to staff perception of the patients role in the ISB. Staff perceptions of their own role in the scenario were also measured on (6) locus and (7) controllability. Higher scores indicate increased perceptions that the behaviour is more internal, universal, global, stable and uncontrollable. 
Again from the previous work of Smith and Willner (2004) participants were asked to rate the likelihood of experiencing 5 emotions in response to the behaviour outlined in the scenario. Similar to the causal explanations sections, a 5-point Likertscale was used for individuals to rate the likelihood of feeling anger, disgust, embarrassment, fear and sympathy.

Measures for risk assessment and management include a 5-point Likert-scale for an item where participants rate the perceived seriousness of the scenario (' 0 ' being 'not serious at all' and '4' being 'very serious'). A second item required participants to rate the likelihood of the behaviour reoccurring if no management strategies were enforced ('0' being 'will not occur' and ' 4 ' being certain to reoccur'). The third item requires participants to make a judgement on the level of supervision required using a 4-point Likert-scale (' 0 ' representing 'no supervision required' to ' 3 ' representing 'requires supervision at all times').

Participants were also asked to rate the importance of 8 management strategies (as seen in table 2), in relation to the outlined scenario, on a 5-point Likert-scale (' 0 ' representing 'important at all' and '4' representing 'extremely important').

\section{Procedure}

Following approval from Nottingham Trent University Research Ethics Committee and agreement from the management of the organisation, staff members at a neurorehabilitation unit in the East Midlands were informed about the proposed research at a multidisciplinary meeting. A questionnaire pack, and a return envelope, was distributed to all qualified staff and direct care staff members. One hundred and twenty-one questionnaires were distributed. Eighty-nine staff (40 qualified and 49 direct care) completed and returned the questionnaire; which equates to a $73.5 \%$ response rate. Due to incomplete data 2 questionnaires (from direct care staff) were omitted. 


\section{Statistical analysis}

Principal components analysis with Varimax rotation was conducted on questionnaire items of 'causal explanations' in order to reduce the number of critical variables. All 15 items loaded on to one of the five factors which accounted for $70 \%$ of the variance (Table 1 highlights all factor loadings of $>0.3$ for clarity).

\begin{tabular}{|c|c|c|c|c|c|}
\hline & \multicolumn{5}{|c|}{ Factor Loading } \\
\hline Item & $\begin{array}{l}\text { Factor } \\
\mathbf{1} \\
\text { (Sexual } \\
\text { motiva- } \\
\text { tion) }\end{array}$ & $\begin{array}{l}\text { Factor } \\
\mathbf{2} \\
\text { (Poor } \\
\text { manage- } \\
\text { ment) }\end{array}$ & $\begin{array}{l}\text { Factor } \\
\mathbf{3} \\
\text { (Atten- } \\
\text { tion } \\
\text { seeking) }\end{array}$ & $\begin{array}{l}\text { Factor } \\
\mathbf{4} \\
\text { (Negative } \\
\text { emotion/ } \\
\text { unstable } \\
\text { mental } \\
\text { health) }\end{array}$ & $\begin{array}{l}\text { Factor } \\
\mathbf{5} \\
\text { (Lacks } \\
\text { educa- } \\
\text { tion) }\end{array}$ \\
\hline Lacks opportunity for meaningful rel. & .886 & & & & \\
\hline Sexual needs not being met & .805 & & & & \\
\hline Trying to seek affection & .779 & & .329 & & \\
\hline Feeling bored at the time & .518 & & .436 & & \\
\hline Feeling aroused at the time & & .820 & & & \\
\hline Feeling impulsive at the time & & .753 & & & \\
\hline Not being supervised properly & & .588 & & & .390 \\
\hline Trying to gain attention & & & .904 & & \\
\hline Learned it gets a response & & & .784 & & \\
\hline Had been a victim of sexual abuse & & & & .777 & \\
\hline Has unmanaged mental health needs & & & & 699 & \\
\hline Feeling angry at the time & & & & .574 & \\
\hline Feeling unhappy at the time & & & & .432 & \\
\hline $\begin{array}{l}\text { Lacks skills to develop meaningful } \\
\text { rel. }\end{array}$ & & & & & .849 \\
\hline Lacks knowledge re. appropriate beh. & & & & & .806 \\
\hline
\end{tabular}

Table 1. Principal components analysis for causal explanations

Visual inspection of the scree plot highlighted eigenvalues $>1$. The factor labels are as follows: sexual motivation (1), poor management (2), attention seeking (3), negative emotion and unstable mental health (4), and lacks education (5). Two items 'trying to seek affection' and 'feeling bored at the time' loaded onto two factors; 'sexual motivation' and 'attention seeking'. Further interpretation resulted in the retention of the items due the distinct cross-over of behaviour. 'Not being supervised properly' also loaded onto 2 factors; 'poor management' and 'lacks education'. A lack of supervision 
indicates 'poor management' in the context of the environment, but this could also impact the opportunity for new learning, particularly if there is a lack of staff guidance. This item, therefore, remained within the analysis.

Similarly, principal components analysis with Varimax rotation was conducted to reduce the management variables. Visual inspection of the scree plot highlighted eigenvalues $>1$. The 8 items were loaded onto 2 factors. These factors accounted for $54 \%$ of the variance. Five of the items loaded solely onto one factor, 'need for action', and two loaded onto the second factor, 'increase awareness' (table 2). One item (report to the police) loaded on to both factors, more heavily on 'need for action'. From further interpretation, this item remained within the analysis as ISB may well require "need for action' but also reporting it to the police may 'increase awareness'; particularly in relation to understanding if ISB is a health or criminal behaviour (Simpson, Blaszczynski \& Hodgkinson, 1999).

\begin{tabular}{lll}
\hline Item & $\begin{array}{l}\text { Factor Loading } \\
\text { Factor 1 } \\
\text { (Need for action) }\end{array}$ & $\begin{array}{l}\text { Factor 2 } \\
\text { (Increase awareness) }\end{array}$ \\
\hline $\begin{array}{l}\text { Refer to mental health } \\
\text { services }\end{array}$ & .746 & \\
Report to the police & .740 & .313 \\
Medication & .719 & \\
$\begin{array}{l}\text { Excluded from location of } \\
\text { incident }\end{array}$ & .604 & \\
Withdrawal of privileges & .624 & \\
Prevent access to victim & .515 & .791 \\
Education on & & .776 \\
sex/relationships & & \\
Verbal prompts & & \\
\hline Table 2. Principal components analysis for management strategies
\end{tabular}

All analyses were completed using SPSS Statistics 24 programme. Parametric tests were utilised due to meeting the required assumptions. A between-subjects $2 \times 2 \times$ 2 MANOVA was conducted. The independent variables consist of the staff role 
(qualified or direct care staff), behaviour (intimate contact IC or non-contact NC) and age of the victim (child or adult). Such analysis was used to determine the effects of these variables on the 22 dependent variables from the questionnaire (as outlined in

table 3). Interactions of the independent variables highlighted a significant three-way interaction $(\mathrm{p}<0.05)$ but failed to highlight any two-way interactions. In addition to exploring the three-way interaction, significant main effects regarding the independent variables are investigated.

Relationships were analysed using partial correlation coefficients for the risk variables. This test focused primarily on the effects across the staff roles controlling for behaviour and age of victim.

Though caution must be taken due to a small sample size, to determine the effects of causal explanations, attributions and emotional responses on the risk variables (seriousness, risk of recurrence, supervision, need for action and increase awareness) stepwise multiple regression analyses were conducted. In order to ascertain the effect of the staff role this was carried out individually for the two groups.

\section{Results}

The MANOVA produced a three-way interaction $(\lambda=.55, \mathrm{~F}(22,58)=2.123$, $\mathrm{p}<0.05)$ between staff role, behaviour and age of victim. Further analysis revealed significant three way interactions for emotional response of embarrassment, perception of seriousness and the causal explanation of poor management.

As seen in figure 1, qualified staff expressed more embarrassment when the ISB was directed towards a child than towards an adult but only in the intimate contact scenario. Conversely, direct care staff expressed more embarrassment when ISB was directed towards a child than towards an adult but only in the non-contact scenario. 


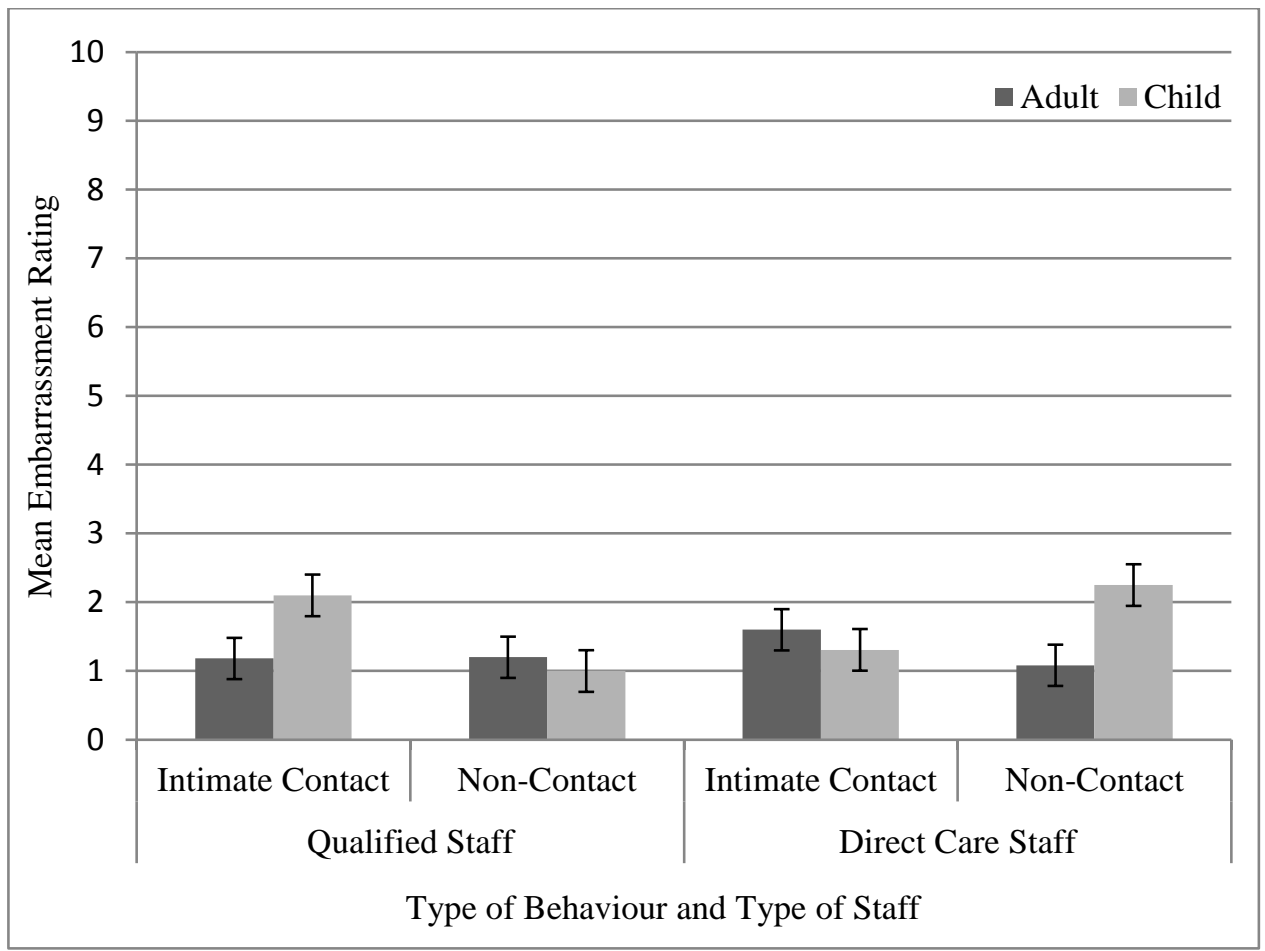

Figure 1. MANOVA interaction effects of Embarrassment. Error bars show $1 \pm$ standard error of the mean.

Figure 2 shows that for the 'perception of seriousness' the three way interaction revealed that when comparing contact with non-contact ISB, direct care staff rated both as equal and highly serious for children whereas qualified staff rated non-contact ISB towards children as less serious than contact ISB. For adult victims direct staff saw contact as more serious than non-contact whereas qualified staff saw both as equally less serious. 


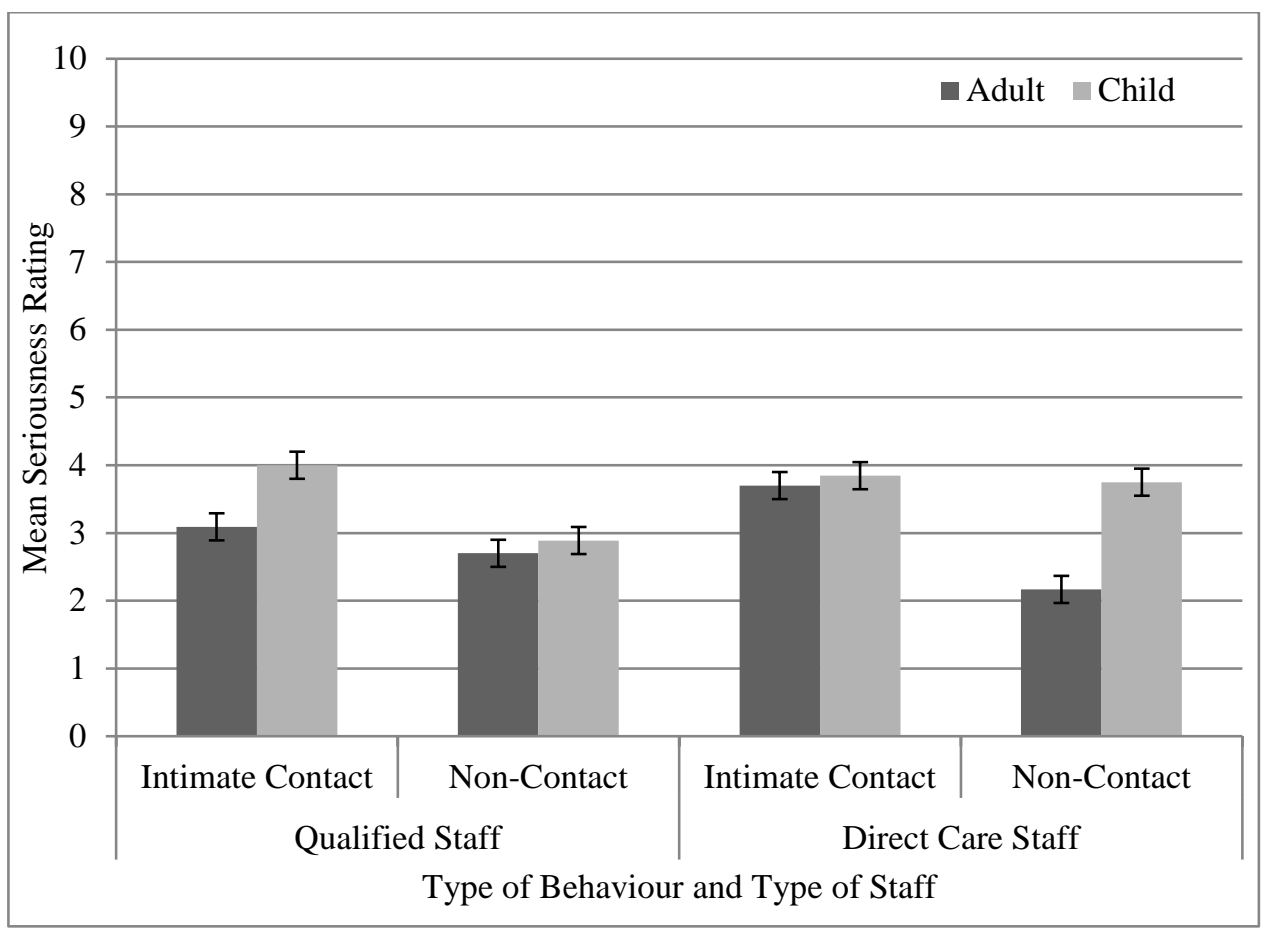

Figure 2. MANOVA interaction effects of Seriousness. Error bars show $1 \pm$ standard error of the mean.

The three way interaction for poor management, figure 3 , showed that both staff types rated non-contact as less likely to be explained by poor management than intimate contact but only qualified staff perceived such explanation to be more likely for a child than adult victim. 


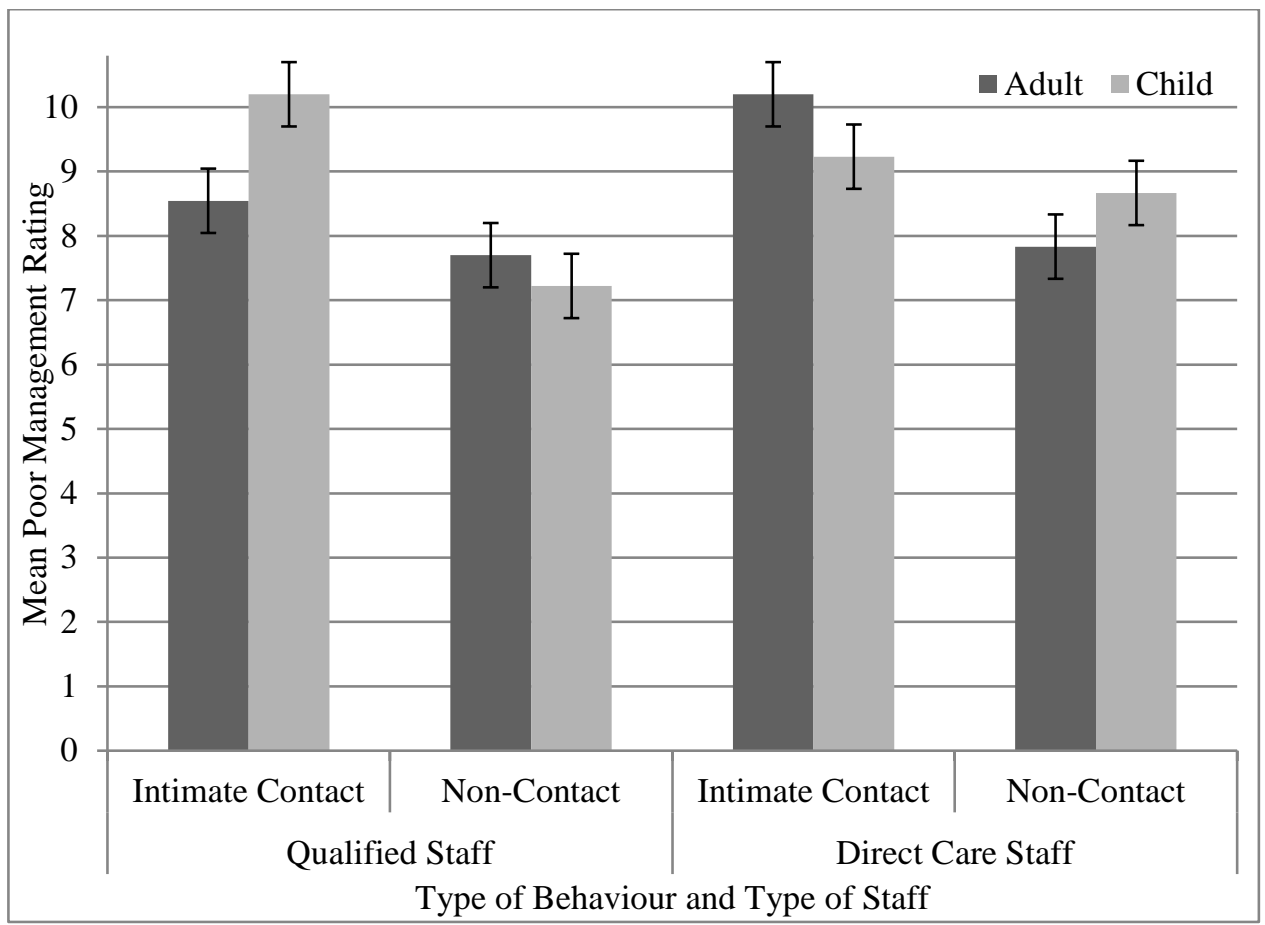

Figure 3. MANOVA interaction effects of Poor Management. Error bars show $1 \pm$ standard error of the mean.

In an attempt to further understand the differences across the three independent variables the main effects are reported (see Table 3).

\section{Behaviour (Intimate vs. Non-contact ISB)}

Poor management was rated to be a more likely cause for intimate contact ISB than non-contact ISB $(F(1,79)=17.625, \mathrm{p}<0.001)$, though for non-contact ISB attention seeking was rated as a more likely cause $(F(1,79)=26.769, \mathrm{p}<0.001)$. The emotional response of fear $(\mathrm{F}(1,79)=5.114, \mathrm{p}<0.05)$ was expressed more for intimate-contact than for non-contact ISB and more significantly for disgust $(F(1,79)=11.429, p<0.001)$. ISB is perceived to be more serious $(\mathrm{F}(1,79)=32.73, \mathrm{p}<0.001)$ and requires more supervision and need for action $(\mathrm{F}(1,79)=10.635, \mathrm{p}<0.005)$ when the vignette depicted intimatecontact compared to non-contact behaviour. 


\section{Victim Age (Child vs. Adult)}

ISB was found to be more serious if directed towards a child victim than an adult $(\mathrm{F}(1,79)=26.8, \mathrm{p}<0.001)$. Behaviour towards child victims was also rated as requiring more supervision, and greater need for action $(F(1,79)=17.302, \mathrm{p}<0.001)$. Higher ratings of anger, disgust and fear were elicited if the victim was a child. Though marginally significant differing levels of control were attributed; ISB towards a child was rated as more controllable for the patient, but higher attributions for staff control were perceived towards the adult victim.

\section{Staff Role (Qualified vs. Direct Care Staff)}

Types of staff did not differ significantly for risk assessment variables (seriousness and risk of recurrence) yet direct care staff expressed a higher need for supervision than qualified staff $(\mathrm{F}(1,79)=4.527, \mathrm{p}<0.05)$. A similar pattern was reported for 'need for action' $(F(1,79)=21.627, p<0.001)$. Explanations which highlighted sexual motivation, attention seeking or negative emotion and unstable mental health were rated higher for direct care staff. Within this, emotional responses of disgust and more specifically anger $(\mathrm{F}(1,79)=18.137, \mathrm{p}<0.001)$ were also expressed more for direct staff. In addition, direct care staff reported ISB to be more stable $(F(1,79)=5.324, p<0.05)$ and also internal to the staff member than qualified staff $(F(1,79)=3.966, p=0.05)$. 


\begin{tabular}{|c|c|c|c|}
\hline & $\begin{array}{l}\text { Behaviour (IC vs } \\
\text { NC) }\end{array}$ & $\begin{array}{l}\text { Victim Age (C vs } \\
\text { A) }\end{array}$ & $\begin{array}{l}\text { Staff Role (Q vs } \\
\text { DC) }\end{array}$ \\
\hline \multicolumn{4}{|l|}{ Causal Explanation } \\
\hline Sexually Motivated & & & $\mathrm{DC}>\mathrm{Q} * * *$ \\
\hline Poor Management & $\mathrm{IC}>\mathrm{NC} * * * *$ & & \\
\hline Attention Seeking & $\mathrm{NC}>\mathrm{IC} * * * *$ & & $\mathrm{DC}>\mathrm{Q} * * *$ \\
\hline Negative Emotion & & & $\mathrm{DC}>\mathrm{Q} * * *$ \\
\hline Lack of Education & & $\mathrm{C}>\mathrm{A} *$ & \\
\hline \multicolumn{4}{|l|}{ Causal Attribution } \\
\hline \multicolumn{4}{|l|}{ Patient Locus } \\
\hline Patient Control & & $\mathrm{C}>\mathrm{A} *$ & \\
\hline \multicolumn{4}{|l|}{ Universal } \\
\hline \multicolumn{4}{|l|}{ Global } \\
\hline Stability & $\mathrm{NC}>\mathrm{IC} *$ & & $\mathrm{DC}>\mathrm{Q}^{* *}$ \\
\hline Staff Locus (int/ext) & & & $\mathrm{DC}>\mathrm{Q} * *$ \\
\hline Staff Control & & $\mathrm{A}>\mathrm{C} *$ & \\
\hline \multicolumn{4}{|l|}{ Emotional Response } \\
\hline Fear & $\mathrm{IC}>\mathrm{NC} * *$ & $\mathrm{C}>\mathrm{A} * * * *$ & $\mathrm{DC}>\mathrm{Q}^{*}$ \\
\hline Anger & $\mathrm{IC}>\mathrm{NC} *$ & $\mathrm{C}>\mathrm{A} * * *$ & $\mathrm{DC}>\mathrm{Q}^{* * * *}$ \\
\hline \multicolumn{4}{|l|}{ Sympathy } \\
\hline Disgust & $\mathrm{IC}>\mathrm{NC} * * * *$ & $\mathrm{C}>\mathrm{A} * * *$ & $\mathrm{DC}>\mathrm{Q} * * *$ \\
\hline \multicolumn{4}{|l|}{ Embarrassment } \\
\hline \multicolumn{4}{|l|}{ Risk Variable } \\
\hline Recurrence & $\mathrm{NC}>\mathrm{IC} *$ & & \\
\hline Seriousness & $\mathrm{IC}>\mathrm{NC} * * * *$ & $\mathrm{C}>\mathrm{A} * * * *$ & \\
\hline \multicolumn{4}{|l|}{ Management } \\
\hline \multicolumn{4}{|l|}{ Strategy } \\
\hline Supervision & $\mathrm{IC}>\mathrm{NC} * *$ & $\mathrm{C}>\mathrm{A} * *$ & $\mathrm{DC}>\mathrm{Q} * *$ \\
\hline Need for action & $\mathrm{IC}>\mathrm{NC} * * *$ & $\mathrm{C}>\mathrm{A} * * * *$ & $\mathrm{DC}>\mathrm{Q} * * * *$ \\
\hline Increase Awareness & & & \\
\hline \multicolumn{4}{|c|}{ Table 3. MANOVA significant main effects for behaviour (IC vs NC), victim (C vs A) } \\
\hline and staff (Q vs DC). & $0.1, * * p<0$ & $\mathrm{p}<0.01, * * * * \mathrm{p}$ & $001 . \mathrm{IC}=$ intimate \\
\hline
\end{tabular}

Relationship between the risk assessment and management variables

Partial correlations for the risk assessment strategies (seriousness and reoccurrence) and management strategies (supervision, need for action and increased awareness) are reported for the types of staff separately (table 4). The significant effects found are all positive medium correlations. 


\begin{tabular}{|l|l|l|l|l|l|}
\hline & Seriousness & Recurrence & Supervision & Need Action & $\begin{array}{l}\text { Incr. } \\
\text { Awareness }\end{array}$ \\
\hline Seriousness & & 0.093 & $0.358^{*}$ & $0.381^{*}$ & $0.409^{*}$ \\
\hline Recurrence & 0.116 & & 0.137 & 0.276 & 0.241 \\
\hline Supervision & 0.25 & 0.284 & & 0.287 & 0.167 \\
\hline Need Action & 0.093 & $0.374^{*}$ & $0.542^{* *}$ & & 0.291 \\
\hline $\begin{array}{l}\text { Incr. } \\
\text { Awareness }\end{array}$ & 0.053 & 0.070 & 0.179 & 0.103 & \\
\hline
\end{tabular}

Table 4. Partial correlation coefficients for risk assessment and management variables; controlling for behaviour and age of victim. Direct care staff are above the diagonal line and qualified staff are below. $* \mathrm{p}<0.05, * * \mathrm{p}<0.001$

For direct care staff perception of seriousness (but not risk of reoccurrence) was associated with a need for all three management strategies (supervision, need for action and increase awareness). For qualified staff, on the other hand, only risk of recurrence was associated with a management strategy; 'need for action'. In addition, this strategy was also associated with qualified staffs' perception regarding the level of supervision. Factors associated with perceptions of risk assessment and management

Stepwise multiple regression was conducted to ascertain what independent variables (explanations, attributions and emotions) were predictors for specific risk assessment and management perceptions (seriousness, risk of recurrence, supervision level, need for action and increase awareness). The analyses were conducted for each staff group separately. They reported significant stepwise models and explained the variance for the perception of risk assessment and management. The overall results for the separate staff groups are reported in table 5 and 6.

Qualified staff: The risk variable which had the largest number of associated variables was 'seriousness'. An overall model indicated 6 variables (anger, locus, embarrassment, attention seeking, universal attribution and lack of education) that significantly predicted the perception of seriousness of qualified staff, $\mathrm{R}^{2}=0.715$, 
$\mathrm{R}^{2} \mathrm{adj}=0.663, \mathrm{~F}(6,33)=13.766, \mathrm{p}<0.001$. This model accounted for $71.5 \%$ of the variance.

Ratings for the attribution of stability were associated with the risk of recurrence where $30.6 \%$ of the variance was explained with this single model, $\mathrm{R}^{2}=0.306$, $\mathrm{R}^{2} \mathrm{adj}=0.287, \mathrm{~F}(1,38)=16.728, \mathrm{p}<0.001$. In addition, ratings for poor management were also associated with increased supervision, $R^{2}=0.168, R^{2} a d j=0.146, F(1,38)=7.654$, $\mathrm{p}<0.01$, with an explained variance of $16.8 \%$.

\begin{tabular}{|c|c|c|c|c|c|c|c|c|}
\hline & \multicolumn{2}{|c|}{ Seriousness } & \multicolumn{2}{|c|}{ Recurrence } & \multicolumn{2}{|c|}{ Supervision } & \multicolumn{2}{|c|}{ Need Action } \\
\hline & $\begin{array}{l}\text { Model } \\
\text { no. } \\
\beta\end{array}$ & $\begin{array}{l}\text { Adjusted } \\
R^{2}\end{array}$ & $\begin{array}{l}\text { Model } \\
\text { no. } \\
\beta\end{array}$ & $\begin{array}{l}\text { Adjusted } \\
R^{2}\end{array}$ & $\begin{array}{l}\text { Model } \\
\text { no. } \\
\beta\end{array}$ & $\begin{array}{l}\text { Adjusted } \\
R^{2}\end{array}$ & $\begin{array}{l}\text { Model } \\
\text { no. } \\
\beta\end{array}$ & $\begin{array}{l}\text { Adjusted } \\
R^{2}\end{array}$ \\
\hline $\begin{array}{l}\text { Poor } \\
\text { Management }\end{array}$ & & & & & $\begin{array}{l}\text { (1) } \\
0.409\end{array}$ & 0.146 & $\begin{array}{l}\mathbf{l 1}) \\
0.252\end{array}$ & 0.225 \\
\hline $\begin{array}{l}\text { Attention } \\
\text { Seeking }\end{array}$ & $\begin{array}{l}\text { (4) } \\
-0.293\end{array}$ & 0.570 & & & & & & \\
\hline $\begin{array}{l}\text { Lack of } \\
\text { Education }\end{array}$ & $\begin{array}{l}\text { (6) } \\
-0.217\end{array}$ & 0.668 & & & & & & \\
\hline $\begin{array}{l}\text { Patient Locus } \\
\text { (int/ext) }\end{array}$ & $\begin{array}{l}\mathbf{( 2 )} \\
0.323\end{array}$ & 0.445 & & & & & & \\
\hline Universal & $\begin{array}{l}\mathbf{( 5 )} \\
0.249\end{array}$ & 0.619 & & & & & & \\
\hline Stability & & & $\begin{array}{l}\mathbf{( 1 )} \\
0.553\end{array}$ & 0.287 & & & $\begin{array}{l}\text { (3) } \\
0.288\end{array}$ & 0.347 \\
\hline Anger & $\begin{array}{l}\mathbf{l 1}) \\
0.434\end{array}$ & 0.323 & & & & & & \\
\hline Disgust & & & & & & & $\begin{array}{l}\mathbf{( 2 )} \\
0.396\end{array}$ & 0.287 \\
\hline Embarrassment & $\begin{array}{l}\text { (3) } \\
0.313\end{array}$ & 0.509 & & & & & & \\
\hline $\begin{array}{l}\text { Variance } \\
\text { Explained }\end{array}$ & $71.5 \%$ & & $30.6 \%$ & & $16.8 \%$ & & $39.8 \%$ & \\
\hline
\end{tabular}

Table 5. Significant results from the stepwise regression analysis for qualified staff $(\mathrm{p}<0.05)$. Steps for each risk variable are highlighted in bold text along with the corresponding Beta coefficient and Adjusted $\mathrm{R}^{2}$. The total explained variance is written as a percentage $(\%)$. 
Poor management, along with feelings of disgust and the attribution of stability were predictors for the overall model for the perception of 'need for action', $\mathrm{R}^{2}=0.398$, $\mathrm{R}^{2} \mathrm{adj}=0.347, \mathrm{~F}(3,36)=7.919, \mathrm{p}<0.001$. A significant model was not reported for the risk management strategy of 'increasing awareness'.

Direct care staff: Different findings were reported for the direct care staff. No significant models were reported for 'risk of recurrence'. A single one-step model (fear) was a significant predictor for the perception of seriousness, $R^{2}=0.163, R^{2} a d j=0.145$, $F(1,45)=8.773, p<0.005$. This model accounted for $16.3 \%$ of the variance. A greater number of variables were included in the overall model for the risk variable 'supervision' (casual explanation of negative emotion, sympathy, fear, the attribution of staff control and lack of education). The total explained variance was $56.6 \%, \mathrm{R}^{2}=0.566$, $\mathrm{R}^{2} \mathrm{adj}=0.513, \mathrm{~F}(5,41)=10.680, \mathrm{p}<0.001$.

The 'need for action' ratings were predicted by an overall model of 3 variables (fear, poor management and the attribution of patient control), $R^{2}=0.307, R^{2} \operatorname{adj}=0.258$, $F(3,43)=6.339, p<0.001$, with an explained variance of $30.7 \%$. Though ratings for ‘increasing awareness' were not reported for qualified staff, a significant model was highlighted for direct care staff. Three variables (global attribution, sympathy and patient locus of control) reported a $31.7 \%$ explained variance, $R^{2}=0.317, R^{2} a d j=0.270$, $\mathrm{F}(3,43)=6.662, \mathrm{p}<0.001$. 


\begin{tabular}{|c|c|c|c|c|c|c|c|c|}
\hline & \multicolumn{2}{|c|}{ Seriousness } & \multicolumn{2}{|c|}{ Supervision } & \multicolumn{2}{|c|}{ Need Action } & \multicolumn{2}{|c|}{ Incr. Aware } \\
\hline & $\begin{array}{l}\text { Model } \\
\text { no. } \\
\beta\end{array}$ & $\begin{array}{l}\text { Adjusted } \\
R^{2}\end{array}$ & $\begin{array}{l}\text { Model } \\
\text { no. } \\
\beta\end{array}$ & $\begin{array}{l}\text { Adjusted } \\
R^{2}\end{array}$ & $\begin{array}{l}\text { Model } \\
\text { no. } \\
\beta\end{array}$ & $\begin{array}{l}\text { Adjusted } \\
R^{2}\end{array}$ & $\begin{array}{l}\text { Model } \\
\text { no. } \\
\beta\end{array}$ & $\begin{array}{l}\text { Adjusted } \\
R^{2}\end{array}$ \\
\hline $\begin{array}{l}\text { Poor } \\
\text { Management }\end{array}$ & & & & & $\begin{array}{l}\text { (2) } \\
0.281\end{array}$ & 0.201 & & \\
\hline $\begin{array}{l}\text { Negative } \\
\text { Emotion }\end{array}$ & & & $\begin{array}{l}\mathbf{( 1 )} \\
0.545\end{array}$ & 0.202 & & & & \\
\hline $\begin{array}{l}\text { Lack of } \\
\text { Education }\end{array}$ & & & $\begin{array}{l}\mathbf{5}) \\
-0.238 \\
\end{array}$ & 0.513 & & & & \\
\hline $\begin{array}{l}\text { Patient Locus } \\
\text { (int/ext) }\end{array}$ & & & & & & & $\begin{array}{l}\text { (3) } \\
0.284\end{array}$ & 0.080 \\
\hline $\begin{array}{l}\text { Patient } \\
\text { Control } \\
\end{array}$ & & & & & $\begin{array}{l}\text { (3) }- \\
0.270\end{array}$ & 0.258 & & \\
\hline Global & & & & & & & $\begin{array}{l}\mathbf{( 1 )} \\
0.374\end{array}$ & 0.270 \\
\hline Staff Control & & & $\begin{array}{l}\text { (4) } \\
-0.303\end{array}$ & 0.070 & & & & \\
\hline Fear & $\begin{array}{l}\text { (1) } \\
0.404\end{array}$ & 0.145 & $\begin{array}{l}\text { (3) } \\
0.262\end{array}$ & 0.425 & $\begin{array}{l}\mathbf{( 1 )} \\
0.431\end{array}$ & 0.130 & & \\
\hline Sympathy & & & $\begin{array}{l}\mathbf{( 2 )} \\
0.399\end{array}$ & 0.328 & & & $\begin{array}{l}\mathbf{( 2 )} \\
0.297\end{array}$ & 0.203 \\
\hline $\begin{array}{l}\text { Variance } \\
\text { Explained }\end{array}$ & $16.3 \%$ & & $56.6 \%$ & & $30.7 \%$ & & $31.7 \%$ & \\
\hline
\end{tabular}

Table 6. Significant results from the stepwise regression analysis for direct care staff $(p<0.05)$. Steps for each risk variable are highlighted in bold text along with the corresponding Beta coefficient and Adjusted $\mathrm{R}^{2}$. The total explained variance is written as a percentage $(\%)$.

Findings from the MANOVA reported in Table 6 highlight significant differences between the independent variables of behaviour (intimate contact or noncontact) and victim (child or adult). Due to this such predictors were included in the regression analyses to ascertain their association with the risk assessment and management variables. Results show that behaviour and victim have little effect on risk management for both staff groups. Though, perceptions of seriousness for direct care staff, only, are significantly altered when these two variables are incorporated; accounting for $44.1 \%$ of the total variance in the regression model. 


\section{Discussion}

This study explored risk assessment and risk management in the context of inappropriate sexual behaviour and traumatic brain injury. As this project is a particularly under-investigated, somewhat 'taboo', concept of staff practice within TBI services, perceptions of risk assessment and management were explored for two staff roles with differing intervening responsibilities.

\section{Type of behaviour (intimate vs. non-contact behaviour)}

In line with previous literature, this study found, overall, intimate-contact behaviour depicted in the vignettes was rated as more serious than non-contact behaviour (Smith \& Willner, 2004). Direct care staff perceived non-contact and contact ISB to be equally highly serious when directed towards a child. These responses are somewhat reflective of the general public which may be heavily influenced by the media. A recent report has stated "there are no hierarchies when it comes to child maltreatment" (Rapaport, 2015), thus indicating any child abuse is perceived to be serious.

Intimate-contact behaviour also evoked more negative emotional responses of fear and disgust. The perceived risk of recurrence was greater for non-contact behaviour than intimate-contact behaviour, and from further exploring the risk management strategies intimate-contact behaviour was perceived to be in greater need of intervention. It could be assumed that this behaviour was deemed to be at a lower risk of recurring due to the perception of an increased need for intervention and management. In line with previous research, Willner and Smith (2008) also indicated that ISB requires greater intervention for reduction of risk. 


\section{Victim Age (Adult vs. Child)}

Contact ISB towards a child was deemed to be more serious and in need of supervision and intervention than if towards an adult. This corresponds to the sentencing of a sexual assault where harsher sentences are stipulated for those offending against children (Maximum Sentences for Criminal Offences Table List, n.d). In addition, these perceptions could coincide with the significant differences for fear, anger and disgust where offences against a child were more likely to evoke those emotional responses. There is a general consensus that feeling angry and disgruntled is associated with an increased desire for punishment (Johnson, 2009). Though the emphasis in care settings is not on punishment, if staff adopt such views they may somewhat feel the need to reprimand the patients and consequently create issues of a safeguarding nature (Safeguarding people, 2016).

Direct care staff perceived poor management to be a greater causal explanation for intimate-contact ISB towards an adult, rather than to a child. Due to the nature of their role and the environment, direct care staff are more likely to be exposed to ISB directed towards an adult. From this, their attributing explanation may have been primarily based on personal experiences available to them (McClure, 2011). In addition, direct care staff attribute higher levels of internal locus of control (i.e. the cause of the ISB is due to the staff member). As they directly work with the individual they may be less likely to rate poor management as the cause for more serious behaviour (intimate contact towards a child) due to fear of being somewhat accountable.

\section{Staff Group (Qualified vs. Direct Care Staff)}

The overall results confirm the hypothesis. Perceptions are significantly different between direct care and qualified staff where the former perceive ISB to be in greater need of supervision and need for action. In addition they elicited higher levels of 
anger and disgust. Though direct care staff spend considerably more time with the patient it has been postulated that negative attitudes are due to a less theoretical understanding of ISB. This has been shown when comparing students, prison officers and forensic staff. The layperson holds significantly more negative attitudes towards sex offenders and forensic staff hold the most positive attitudes(Ferguson \& Ireland, 2006; Kielsber \& Loos, 2008).

Further to the elevated anger response direct staff perceived the behaviour to be influenced by their own actions. From this, it could be suggested that the expressed anger isn't necessarily in response to the ISB but due to the overall situation. The situational and escalating effects regarding challenging behaviour have previously been highlighted to elicit negative emotions (Ravoux, Baker \& Brown, 2012).

Causal explanations of the staff groups also highlight significant differences. Direct care staff deemed the causation of ISB to be sexually motivated, due to negative emotions and poor mental health and due to seeking attention. Working closely with the patients for lengthy periods of time, direct care staff may somewhat overlook the associated traits of a traumatic brain injury, such as impulsivity, and focus more on the general societal causes of sexual offences(McClure, 2011; Simpson et al, 1999).

Though the perception of seriousness did not differ across the staff groups, further investigation reported that for direct care staff 'seriousness' was associated with the need for increased management and intervention. This was also found in previous research by Smith and Willner (2004), however, such results were highlighted from qualified staff and not the direct care staff. In the current study, risk management strategies were not associated with the perception of 'seriousness' for qualified staff. The participant sample within both studies needs to be considered; the previous study only utilised care managers as 'qualified staff' (Smith \& Willner, 2004), whereas the 
current study incorporated a variety of therapeutic disciplines from the multidisciplinary team (MDT). Different results may have occurred due to the epistemological stance; care managers are likely to have a nursing or medical background which could result in adhering to the medical model, advocating ailments need to be treated (Blaney, 2015). It may be assumed that the direct staff group in the current study are more attuned to this model. Adhering to different models may influence perceptions and attributions to ISB. In relation to the current study, though utilising the whole MDT could provide more robust risk assessment plans this factor alone could account for the discrepancy between studies.

Direct care staff, those who facilitate the behaviour interventions, perceived ISB to be more stable than qualified staff. Similar findings have been reported where police officers, again those intervening, believe the sexual behaviour to be unchangeable (Day, 2014). Interestingly, 'stability' was a significant predictor for 'risk of recurrance' for qualified staff. This suggests that qualified staff perceive the behaviour to be static (i.e. more difficult to treat) and associated to the 'risk of recurrence'. This perception is somewhat similar to the methodological approach of actuarial risk assessments, where clinical judgement is not accounted for (Hart, 1998).

\section{Limitations}

Whilst highlighting a range of important findings regarding staff perceptions of ISB following TBI, it is important to consider the broader picture. As already briefly highlighted, exposure to ISB may influence perceived explanations and attributions regarding the behaviour. It may be that staff assign attributions based on their prior knowledge and experience (McClure, 2011). Further to this, the use of vignettes could skew responses. Though they instil aspects of control and consistency across conditions, 
they are not 'real-life' and may depict scenarios which the staff have, or have not, been exposed to.

Another methodological factor to consider for future research regarding ISB following TBI is the idea of including hypersexuality as a causal attribution. Though impulsivity and disinhibition were added to the original questionnaire used by Smith and Willner (2004), the construct of increased sex drive, which encompasses such factors, was not specifically included (Eghwrudjakpor \& Essien, 2008). This element may enhance the current results.

Utilising a pre-existing questionnaire from previous research can aid exploration of certain phenomena; however, it may not acknowledge all relevant factors. There is a wide variety of treatments and therapy for ISB in those with neurological disorders (De Giorgi \& Series, 2016). The questionnaire covered just a small proportion of techniques and was heavily focused on behaviour methods (of which were also limited). Other strategies to consider include environmental strategies, redirection, occupation of time, psychoeducation, and pharmacological methods (De Giorgi \& Series, 2016).

\section{Implications and recommendations}

Different roles, responsibilities and perceptions may create conflict when managing the displayed ISB. Direct care staff appear to be more concerned with making decisions based on the seriousness, along with the level of behaviour and age of victim, whereas the qualified staff focus on the risk of recurrence and the service response. The latter corresponds to the rationale of utilising risk assessment procedures: to predict and reduce the likelihood of behaviour (Hart, 1998).

The awareness of a patients' history may influence staff attributions which contribute to such assessment. Here, questions need to be asked regarding whether the ISB is a criminal or health related behaviour. Those who engage in ISB following a TBI 
are rarely criminally reprimanded and are more commonly treated within a health context. Simpson et al (1990) reported that TBI is a distinct etiological factor in ISB due to lack of pre-injury sexual offending history. These findings, however, are specific to that sample of patients, and therefore, each case of ISB should be assessed adequately in order to determine an appropriate course of action.

Results from this investigation highlight that staff groups perceive causes and appropriate management strategies to ISB differently. One possible reason for this could be due to training and experience. Though all participants had attended Brain Injury Awareness training, where they were provided with some information about ISB, there could well be differences in prior qualifications and exposure to ISB. In addition the different staff groups may also have different expectations regarding the training based on their epistemological stance (Blaney, 2015). For example, direct care staff may be concerned with responding to the behaviour rather than understanding the theoretical components of it. This could therefore explain the differences in causation and management across the two staff groups.

As the qualified staff make decisions regarding care plans and strategies it is evident they consider the service and management implications when assessing risk of recurrence. For example, increased frequency of the ISB would somewhat impact on the level of supervision required and consequently have an impact on staffing ratios and associated costs. Due to budget cutting within healthcare services it is within the qualified staffs interest to manage risk situations effectively with minimal financial implications (Stone, 2015).

Due to the different responses towards ISB from both staff groups, a 'needs analysis' could be conducted with all staff to determine their individual training and support needs in relation to the management of this specific behaviour. Specific training 
techniques, such as Positive behavioural support (PBS) could be utilised. This training has been successful in increasing confidence and altering staff attributions regarding challenging behaviour (Davies, Griffiths, Liddiard, Lowe \& Stead, 2015). Further to this, both staff staffgroups should also communicate their perceptions each other. This allows for collaborative development of appropriate strategies.

In terms of future directions, it is important to ascertain perceptions utilising real-life, as opposed to researcher-generated scenarios to improve the validity of such findings. With research highlighting the impact negative emotions have on perceptions and management, exploration is required to further determine the reasons for such feelings.

In conclusion, it is evident that qualified and direct care staff hold differing perceptions regarding risk assessment and management of ISB following TBI. Though it can be perceived qualified staff are more knowledgeable in terms of understanding the behaviour, it is the direct care staff who spend extensive periods of time with the patients and could be perceived as more experienced. In addition, direct care staff are typically the ones who are required to make judgements and facilitate management strategies. As such, it is important for the two staff groups to communicate in order to increase awareness of the different perspectives. Consequently, this could reduce discrepancies, reduce staff conflict and provide increased cohesion within clinical practice.

\section{Acknowledgements}

The author would like to express gratitude to those within the Neurorehabilitation service where this project was conducted; to those who gave approval for this work and to those who participated. 


\section{Conflicts of Interest}

In accordance with Taylor \& Francis policy and my ethical obligation as a researcher, I am reporting that I was an employee of the organisation where this research was conducted. No financial or business gain, to either party, was obtained from this exploratory piece. I have disclosed those issues fully to Taylor \& Francis.

\section{References}

Alderman, N., Knight, C., \& Henman, C. (2002). Aggressive behaviours observed within a neurobehavioural rehabilitations service: utility of the OAS-MNR in clinical audit and applied research. Brain Injury, 16 (6), 469-489. Doi:

$10.1080 / 02699050110118458$

Alderman, N., Major, G., \& Brooks, J. (2016). What can structured professional judgement tools contribute to management of neurobehavioural disability? Predictive validity of the Short-Term Assessment of Risk and Treatability (START) in acquired brain injury. Neuropsychological Rehabilitation, 11, 1-18. Doi

10.1080/09602011.2016.1158115.

Alexander, N., \& Gomez, M. T. (2017). Pleasure, sex, prohibition, intellectual disability, and dangerous ideas. Reproductive Health Matters, 25 (50), 114-120. Doi $10.1080 / 09688080.2017 .1331690$

Bailey, B. A., Hare, D. J., Hatton, C., \& Limb, K. (2006). The response to challenging behaviour by care staff: emotional responses, attributions of cause and observations of 
practice. Journal of Intellectual Disability Research, 50 (3), 199-211. Doi

10.1111/j.1365-2788.2005.00769.

Bezeau, S. C., Bogod, N. M., \& Mateer, C. A. (2004). Sexually intrusive behaviour following brain injury: approaches to assessment and rehabilitation. Brain Injury, 18 (3), 299-313. Doi 10.1080/02699050310001617398

Blaney, P. H. (2015). Medical model of mental disorders. The Encyclopaedia of Clinical Psychology. Retrieved July 12, 2016 from http://onlinelibrary.wiley.com/doi/10.1002/9781118625392.wbecp382

Cottle, M., Kuipers, L., Murphy, G., \& Oakes, P. (1995). Expressed emotion, attributions and coping in staff who have been victims of violence incidents. Mental Handicap Research, 8 (3), 168-183. Doi 10.1111/j.1468-3148.1995.tb00153.x

Dagnan, D., \& Cairns, M. (2005). Staff judgements of responsibility for challenging behaviour of adults with intellectual disabilities. Journal of Intellectual Disability Research, 49 (1), 95-101. Doi 10.1111/j.1365-2788.2005.00665.x

Dagnan, D., \& Weston, C. (2006). Physical intervention with people with intellectual disabilities: the influence of cognitive and emotional variables. Journal of Applied Research in Intellectual Disabilities, 19 (2), 219-222. Doi 10.1111/j.14683148.2005.00262.x

Davies, B., Griffiths, J., Liddiard, K., Lowe, K., \& Stead, L. (2015). Changes in staff confidence and attributions for challenging behaviour after training in positive 
behavioural support within a forensic medium secure service. The Journal of Forensic Psychiatry \& Psychology, 26 (6), 847-861. Doi 10.1080/14789949.2015.1072574

Day, A. (2014). Professional attitudes to sex offenders: implications for multiagency and collaborative working. Sexual Abuse in Australia and New Zealand, 6 (1), 12-19.

De Giorgi, R., \& Series, H. (2016). Treatment of inappropriate sexual behaviour in dementia. Current Treatment Options in Neurology, 18 (9), 41. Doi 10.1007/s11940016-0425-2.

Eghwrudjakpor, P., \& Essien, A. (2008). Hypersexual Behavior Following Craniocerebral Trauma An Experience with Five Cases. The Libyan Journal of Medicine, 3 (4), 192-194. Doi 10.4176/080908

Ferguson, K., \& Ireland, C. (2006). Attitudes towards sex offenders and the influence of offense type: a comparison of staff working in a forensic setting and students. The British Journal of Forensic Practice, 8 (2), 10-19. Doi 10.1108/14636646200600009.

Hart, S. D. (1998). The role of psychopathy in assessing risk for violence: Conceptual and methodological issues. Legal and Criminological Psychology, 3 (1), 121-137. Doi 10.1111/j.2044-8333.1998.tb00354.x

Hastings, R. P. (1997). Measuring staff perceptions of challenging behaviour: The Challenging Behaviour Attributions Scale (CHABA). Journal of Intellectual Disability Research, 41 (6), 495-501. Doi 10.1111/j.1365-2788.1997.tb00742.x 
Hayward, L. E., Robertson, N., \& Knight, C. (2012). Inappropriate sexual behaviour and dementia: an exploration of staff experiences. Dementia, 12 (4), 463-480. Doi $10.1177 / 1471301211434673$.

Healthcare assistant. (n.d.). Retrieved December 22, 2017 from

https://www.healthcareers.nhs.uk/explore-roles/wider-healthcare-team/roles-widerhealthcare-team/clinical-support-staff/healthcare-assistant

Johnson, C., Knight, C., \& Alderman, N. (2006). Challenges associated with the definition and assessment of inappropriate behaviour amongst individuals with an acquired neurological impairment. Brain Injury, 20 (7), 687-693. Doi $10.1080 / 02699050600744137$

Johnson, D. (2009). Anger about crime and support for punitive criminal justice policies. Punishment \& Society, 11 (1), 51-66. Doi 10.1177/1462474508098132.

Kjelsbery, E., \& Loos, L. H. (2008). Conciliation or condemnation? Prison employees and young peoples' attitudes towards sexual offenders. The International Journal of Forensic Mental Health, 7 (1), 95-103. Doi 10.1080/14999013.2008.9914406.

Knight, C., Alderman, N., Johnson, C., Green, S., Birkett-Swan, L., \& Yorston, G. (2008). The St Andrew's Sexual Behaviour Assessment (SASBA): Development of a standardised recording instrument for the measurement and assessment of challenging 
sexual behaviour in people with progressive and acquired neurological impairment. Neuropsychological Rehabilitation, 18 (2), 129-159. Doi 10.1080/09602010701822381

Lambrechts, G., Kuppen, S., \& Maes, B. (2009). Staff variables associated with the challenging behaviour of clients with severe or profound intellectual disabilities. Journal of Intellectual Disability Research, 58 (7), 620-632. Doi 10.1111/j.13652788.2009.01162.x.

Lawrie, B., \& Jillings, C. (2004). Assessing and addressing inappropriate sexual behavior in brain-injured clients. Rehabilitation Nursing, 29 (1), 9-13. Doi 10.1002/j.2048-7940.2004.tb00293.x

MacKinlay, L., \& Langdon, P.E. (2009). Staff attributions towards men with intellectual disability who have a history of sexual offending and challenging behaviour. Journal of Intellectual Disability Research, 53 (9), 807-815. Doi 10.1111/j.13652788.2009.01194.x.

Maximum Sentences for Criminal Offences Table List. (n.d.). Retrieved July 12, 2016 from http://www.thelawpages.com/court-cases/maximums.php

McClure, J. (2011). The role of casual attributions in public misconceptions about brain injury. Rehabilitation Psychology, 56 (2), 85-93. Doi 10.1037/a0023354 
Murray, J., Thomson, M. E., Cooke, D. J., \& Charles, K. E. (2011). Influencing expert judgement: Attributions of crime causality. Legal and Criminological Psychology, 16 (1), 126-143. Doi 10.1348/135532510X490183

Peterson, C., Semmel, A., von Baeyer, C., Abramson, L. Y., Metalsky, G. I., \& Seligman, M. E. P. (1982). The attributional style questionnaire. Cognitive Therapy and Research, 6 (3), 287-299. Doi 10.1007/BF01173577

Ponsford, J. (2003). Sexual changes associated with traumatic brain injury. Neuropsychological rehabilitation, 13 (1-2), 275-289. Doi: $10.1080 / 09602010244000363$

Pulsford, D., Duxbury, J. A., \& Hadi, M. (2011). A survey of staff attitudes and responses to people with dementia who are aggressive in residential care settings. Journal of Psychiatric and Mental Health Nursing, 18 (2), 97-104. Doi 10.1111/j.13652850.2010.01646.x

Rapaport, L. (2015). Emotional child abuse may be just as bad as physical harm. Retrieved from http:// http://www.reuters.com/article/us-health-childabuse-emotional$\underline{\text { idUSKCNOSD2C720151019 }}$

Ravoux, P., Baker. P., \& Brown, H. (2012). Thinking on your feet: understanding the immediate responses of staff to adults who challenge intellectual disability services. Journal of Applied Research in Intellectual Disabilities, 25 (3), 189-202. Doi 10.1111/j.1468-3148.2011.00653.x. 
Sabaz, M., Simpson, G, K., Walker, A. J., Rogers, J. M., Gillis, I., \& Strettles, B. (2014). Prevalence, comorbidities, and correlates of challenging behaviour among community-dwelling adults with severe traumatic brain injury: a multicentre study. Journal of Head Trauma Rehabilitaiton, 29 (2), 19-30. Doi 10.1097/HTR.0b013e31828dc590

Safeguarding people. (2016). Retrieved July 12, 2016, from https://www.cqc.org.uk/content/safeguarding-people.

Simpson, G., Blaszczynski, A., \& Hodgkinson, A. (1999). Sex offending as a psychosocial sequela of traumatic brain injury. Journal of Head Trauma Rehabilitation, 14 (6), 567-580. Doi 10.1097/00001199-199912000-00005

Simpson, G. K., Sabaz, M., \& Daher, M. (2013). Prevalence, clinical features, and correlates of inappropriate sexual behaviour after traumatic brain injury: a multicentre study. Journal of Head Trauma Rehabilitation, 28 (3), 202-210. Doi 10.1097/HTR.0b013e31828dc5ae

Smith, M., \& Willner, P. (2004). Psychological factors in risk assessment and management of inappropriate sexual behaviour by men with intellectual disabilities. Journal of Applied Research in Intellectual Disabilities, 17 (4), 285-297. Doi 10.1111/j.1468-3148.2004.00210.x 
Stone, J. (2015, November 27). George Osborne actually cut public health budget by 20 per cent despite NHS promises, analysis finds. Independent. Retrieved from http://www.independent.co.uk/news/uk/politics/george-osborne-actually-cut-healthbudget-by-20-per-cent-despite-nhs-promises-analysis-finds-a6751311.html

Tynan, H., \& Allen, D. (2002). The impact of service user cognitive level on carer attributions for aggressive behaviour. Journal of Applied Research in Intellectual Disabilities, 15 (3), 213-223. Doi 10.1046/j.1468-3148.2002.00120.x

Weatherhead, S., Newby, G., \& Skirrow, P. (2012). Brain injury professionals’ perspective on risk assessment. Social Care and Neurodisability, 3 (2), 77-88. Doi $10.1108 / 20420911211240939$

Willner, P., \& Smith, M. (2008). Can attribution theory explain carers' propensity to help men with intellectual disabilities who display inappropriate sexual behaviour? Journal of Intellectual Disability Research, 52 (1), 79-88. Doi 10.1111/j.13652788.2007.00989.x. 